\title{
Study on the Activity of Ag/Nylon 6, 10 Nanocomposite Against Escherichia coli
}

\author{
Rebaz A. Omar ${ }^{1}$, Awara K. Smail ${ }^{2}$ and Karzan A. Omar ${ }^{1 *}$ \\ ${ }^{1}$ Koya University, Faculty of Science, Department of Chemistry, Daniel Mitterrand Boulevard \\ road, 44023 and Koya, Kurdistan Region-Iraq \\ ${ }^{2}$ Koya University, Faculty of Science, Department of Biology, Daniel Mitterrand Boulevard \\ road, 44023 and Koya, Kurdistan Region-Iraq \\ *Corresponding author
}

A B S T R A C T

Keywords

Nylon 6,10,

Ag-nylon 6,10

Nanocomposite,

XRF, Antibacterial.

Article Info

Accepted:

25 March 2016

Available Online:

10 April 2016

\section{Introduction}

Polymers nanomaterials are more interested in the design daily life requirements due to their safety and friendly with the environment (Crespy and Landfester, 2007). Recently, the new type of polymer nanocomposites has been reported with high improved properties over neat polymers (Zhang et al., 2003; Leuteriz et al., 2003). Nylon was the first commercially successful synthetic polymer, consist of segments of polyethylene $\left(\mathrm{CH}_{2}\right)$ n separated by peptide units (NH-CO) which are parallel or antparallel:

Nylon-n:-[-(NH-CO)-(-CH2)n-]-

Nylon-m,n:-[-(NH-CO)-(CH2)n-2-(CO-

$\mathrm{NH})-(\mathrm{CH} 2) \mathrm{m}-]-$
The unit of the peptide was provided hydrogen bonding between polymer chains giving nylon some of its unique properties (Dasgupta et al., 1996). Nylon is a polar synthetic polyamide can be prepared from adipoyl chloride and hexamethylene diamine to form a linear nylon 6,10. It is particular nylon is made of units of 6 carbons between two nitrogen atoms, an amide linkage, another unit of 10 carbons (Beecroft and Ober, 1997). Metal nanoparticles have several applications in the various areas such as catalysis (Ying et al., 1999), magnetic (Morey et al., 2000), biomedical materials (Kong and Jang, 2008) and optoelectronic (Liu et al., 1998; Schneider et al., 2000). The metal/polymer nanoparticles have the 
potential advantage due to their size particles and distribution of dispersed of metal nanoparticles can be controlled depending on the properties of the host polymer (Zhang et al., 1999; Shi et al., 2011). However, metal nanoparticles often have the tendency to aggregate in the polymer matrix during nanofiber formation. Hence, a facility and feasible approach to attain good dispersion of nanoparticles in the polymer nanofiber matrix is highly desirable (Park at al., 2009). The Controlling shape of nanoparticles is important for chemical, physical, thermal, optical, electric, magnetic and catalytic properties of nanoparticles (Xia et al., 2003; Wu et al., 2001; Murphy, 2002; El-Sayed, 2001; Maier et al., 2003) and dispersion of nanoparticles has an effect on the properties of nanoparticles composition (Cai et al., 2010). Therefore, the Tadros (Tadros, 1993) divided the dispersion of ultrafine particles in medium into: (i) Wetting of particles in dispersion medium. (ii). The breaking of aggregations into mono-dispersing particles or smaller aggregations. (iii) Stabilization of monodispersing particles and smaller aggregations against re-agglomeration. During the past decades, silver nanocrystals, such as nanoparticles, nanorods, nanotubes, and nanowires, have received much attention due to their different physical and chemical properties in comparison to bulk silver (Huang et al., 2015). In this paper, we prepared nylon 6,10 by interfacial synthesis technique from 1,6 hexamethylene diamine with Sebacyl chloride as shown in Figure 1, then loaded with different concentration of silver nitrate to form Ag/nylon nanocomposite and their activity studied against $E$. coli bacteria.

\section{Materials and Methods}

1,6 hexamethylene diamine, Sebacyl chloride, silver nitrate (AgNO3) and sodium borohydride (NaBH4) were provided by Koya University. All Chemicals were used without further purification. Distilled water was used for all the synthesis and measurements.

\section{Synthesis of Nylon 6,10}

Nylon 6,10 was synthesized by interfacial synthesis technique. In addition $20 \mathrm{ml}$ of 0.5 weight percent of sebacoyl chloride in cyclohexane to $20 \mathrm{ml}$ of 0.5 weight percent 1,6-hexanediamine in water. The polymer was collected from the interface of the twophase.

\section{Synthesis of Ag-loaded Nylon 6, 10}

The fabricated nylon 6,10 put in distilled water for $48 \mathrm{~h}$ to remove all interference and solvent. Then, the swollen nylon was put in an aqueous solution of the different concentration of silver nitrate $(0.5 \mathrm{mM}$, $1.5 \mathrm{mM}, 2 \mathrm{mM})$ in the present of $0.5 \mathrm{mM}$ sodium borohydride for 24 hours at $30{ }^{0} \mathrm{C}$ until the different dark color of nylon 6.10 nanoparticles which was indicated the formation of $\mathrm{Ag}$ nanoparticles within the nylon 6,10 network.

The constant weight was gained by washing the fabric with distilled water for 10 second and dried in the oven at $45^{\circ} \mathrm{C}$ for 12 hours.

\section{Antibacterial Performance}

The antimicrobial assay of a sample was performed by disc diffusion method as described by Kirby-Bauer. Loop full growths from bacterial isolate were inoculated into nutrient broth incubated at $37^{\circ} \mathrm{C}$ for 18 hours. The bacterial suspensions were diluted with normal saline. Adjust the turbidity and compare with standard tube (McFarland number 0.5) to yield a uniform suspension. A cotton swab was dipped and 
streaks into adjustment suspension the entire Mueller-Hinton agar. Sample pleats or discs were gently pressed on the surface of the agar. The plates were incubated overnight at $37^{\circ} \mathrm{C}$ while the antibiotic diffuses from the disc into the agar. After incubation, the plates were examined for the presence of inhibition zones.

\section{Results and Discussion}

$\mathrm{XRF}$ is an effective method of analyzing silver metals, thin films and nylon polymers. The polymers (nylon) samples were placed in the chamber and measured by $20 \mathrm{~mm}$ diaphragm in the vacuum. X-ray spectra were obtained using $\mathrm{RX} 9, \mathrm{Cu}$, Mo and $\mathrm{Al}$ conditions. In these analyses, the $\mathrm{X}$-ray tube current was set to approximately $1 \mathrm{~mA}$ for the RX9 target and into $0.5 \mathrm{~mA}$ for other targets. The X-ray tube voltage has been set to $25 \mathrm{kV}$ only for the RX9 and $50 \mathrm{kV}$ for $\mathrm{Cu}$, Mo and $\mathrm{Al}$ targets. The X-ray measuring time was only $200 \mathrm{~s}$ for the Al target and $100 \mathrm{~s}$ for other targets. Silver metals were higher energy (22 Kev) and appear in $\mathrm{Al}$ targets.

Figure 2 shows the X-ray spectra for polymer and fabric. When the detector absorbs fluorescence, its proportion conductance was a change in the energy of the fluorescence which is processed by the electronic. The signal of fluorescent on horizontal axis was measured in kiloelectron volts and the intensity occurrence per second on the vertical axis. The energy of the fluorescent has identified the elements during the measurements. Figure 2a shows the only strong intensity of peak for nylon 6,10 and the strong intensity of peaks of silver nanoparticles can be observed at different concentration in fabricating samples as shown in Figure 2b, 2c, and $2 \mathrm{~d}$ which are indicated the formation of Ag/nylon 6,10 nanocomposite

Figure.1 Synthesis of Nylon-6,10 Fibers

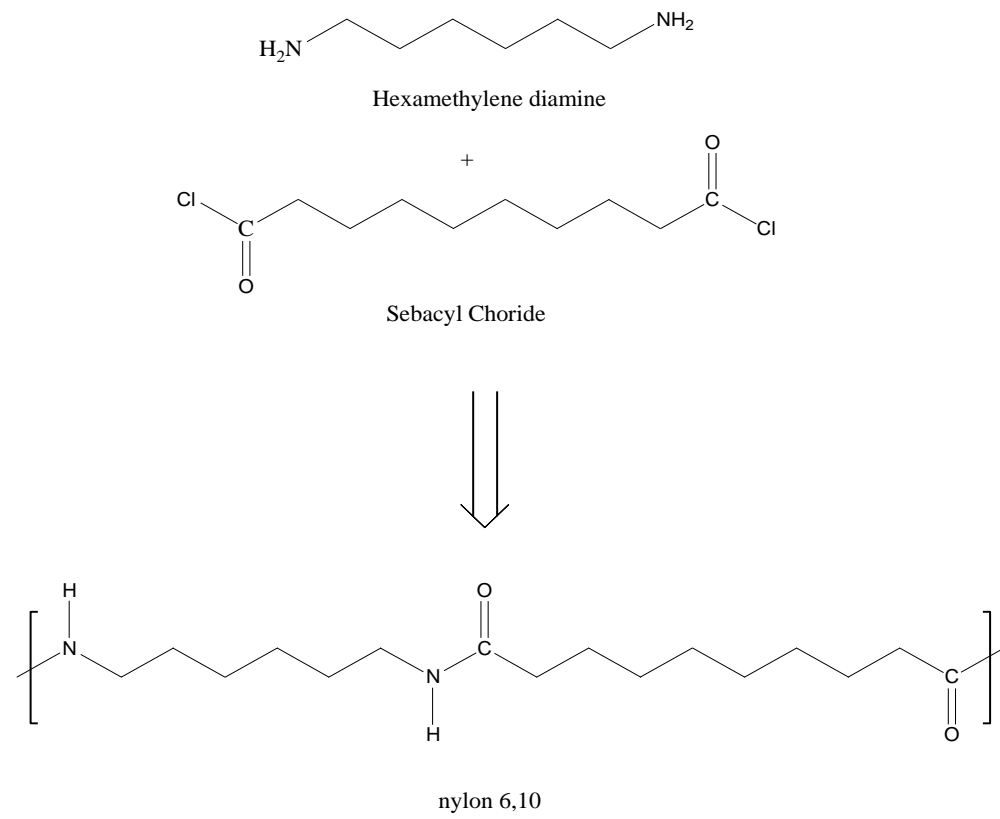


Figure. 2 X-ray Spectra for Nylon a) Nylon without $\mathrm{Ag}$ b) Nylon with $2 \mathrm{mM} \mathrm{AgNO}_{3}$ c) Nylon with $1 \mathrm{mM} \mathrm{AgNO} 3$ d) Nylon with $0.5 \mathrm{mM} \mathrm{AgNO}_{3}$
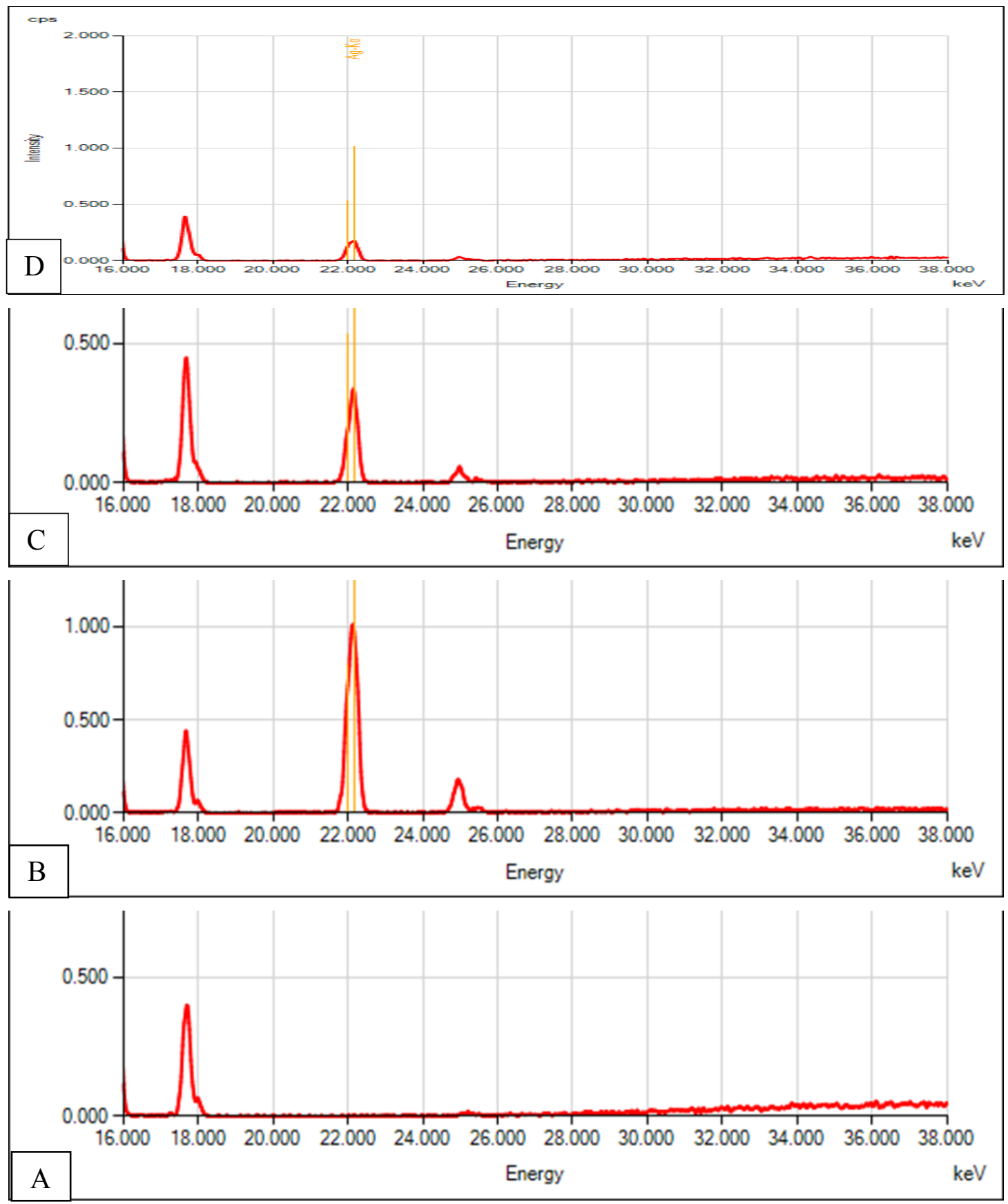
Figure.3 Antibacterial Activity of Ag/nylon 6,6 Nanocomposite against E. coli a) Nylon without $\mathrm{Ag}$ b) Nylon with $2 \mathrm{mM} \mathrm{AgNO}_{3}$ c) Nylon with $1 \mathrm{mM} \mathrm{AgNO}_{3}$ d) Nylon with $0.5 \mathrm{mM}$ $\mathrm{AgNO}_{3}$

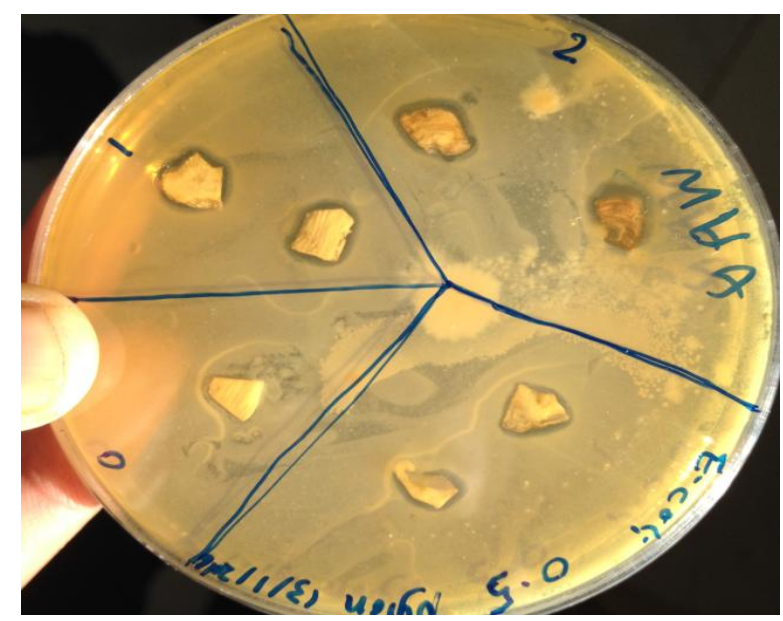

Antibacterial Activity of Ag/nylon 6,10 Nanocomposite against $E$. coli

The antibacterial activity of the fabric was tested against E. coli bacteria. For qualitative measurement of antibacterial activity, the Ag-loaded fabric was cut into 6$8 \mathrm{~mm}$ diam. Discs and tested using the modified agar diffusion assay (disc test). The plates were examined for possible clear zones after incubation at the $30^{\circ} \mathrm{C}$ for 3 hours. The presence of a clear zone around the circular disc on the plate medium was recorded as an inhibition against the microbial species as shown in Figure 3. The nylon 6,10 without loading does not have activity against $E$. coli, but when loaded with different concentration of silver shows activity against $E$. coli and the antibacterial activity of fabric depends on the concentration of $\mathrm{Ag}$ used for loading nylon 6,10 .

In conclusion, The Ag/nylon 6,10 nanocomposite successfully synthesized by reduction method and sodium borohydriate was used as reducing agent. The synthesized Ag/nylon 6, 10 nanocomposite was characterized by XRF for indicating a formation of the nanocomposite. The nylon 6,10 and the fabric at different concentration of silver was tested against the $E$. coli. The effectiveness of fabric as antibacterial observed against $E$. coli bacteria.

\section{Acknowledgment}

The authors are grateful to the staff of the Chemistry, Biology and Genetic center staff department for their support and cooperation.

\section{References}

Beecroft, L.L., Ober, C.K. (1997). Nanocomposite materials for optical applications. Chemistry of Materials, 9, pp. 1302-1317.

Crespy, D., Landfester, k. (2007). Preparation of Nylon 6 Nanoparticles and Nanocapsules by Two Novel Miniemulsion/Solvent Displacement Hybrid Techniques. Macromolecular Chemistry and Physics, 208, pp.457466.

Cai, F.L., Lin, Y.Z., Qian, H. (2010). Dispersion of nano-silica in monomer casting nylon6 and its effect on the 
structure and properties of composites. Express Polymer Letters, 4, pp. 397-403.

Dasgupta, S., Hammond, W.B., Goddard, W.A. (1996). Crystal structures and properties of nylon polymers from theory. J. Am. Chem. Soc, 118, pp.12291-12301.

El-Sayed, A.M. (2001). Some Interesting Properties of Metals Confined in Time and Nanometer Space of Different Shapes. Acc. Chem. Res, 34,pp. 257-264.

Huang, Q., Shen, W., Tan, R., Xu, W., Song, W. (2015). Separation of Silver Nanocrystals for Surfaceenhanced Raman Scattering Using Density Gradient Centrifugation. Journal of Materials Science \& Technology, 31, pp. 834-839.

Kong, H., Jang, J. (2008). Antibacterial Properties of Novel Poly(methyl methacrylate) Nano Fiber Containing Silver Nanoparticles. Langmuir, 24, pp. 2051-2056.

Leuteritz, A., Pospiech, D., Kretzschmar, B., Willeke, M., Jehnichen, D., Jentzsch, U., Grundke, K., Janke, A. Progress in Polypropylene-Nanocomposite Development. Advanced Engineering Materials, 5, pp. 678-681.

Liu, J., Feng, X., Fryxell, G.E., Wang, L., Kim, A.Y., Gong, M. (1998). Hybrid mesoporous materials with functionalized monolayers. Advanced Materials, 10, pp. 161-165.

Morey, M.S., Bryan, J.D., Schartz, S., Stuchy, G.D. (2000). Pore surface functionalization of MCM-48 mesoporous silica with tungsten and molybdenum metal centers: perspectives on catalytic peroxide activation. Chemistry of Materials, 12, pp. 3435-3444.

Murphy, J.C. (2002). Nanocubes and nanoboxes. materials Science, 298,pp. 2139-2141.

Maier, A.S., Kik, G.P., Atwater, A.H., Meltzer, S., Harel, E., Koel, E.B., Requicha, A. (2003). Local detection of electromagnetic energy transport below the diffraction limit in metal nanoparticle plasmon waveguides. Nat. Mater, 2, pp. 229-232.

Park, S.W., Bae, H.S., Xing, Z.C., Kwon, O., Huh, M.W., Kang, I.K. (2009). Preparation and properties of silvercontaining nylon 6 nanofibers formed by electrospinning. J. Appl. Polym. Sci, 112, pp. 2320-2326.

Schneider, J.J., Czap, N., Hagen, J. (2000). Metallorganic routes to nanoscale iron and titanium oxide particles encapsulated in mesoporous alumina: formation, physical properties, and chemical reactivity. Chemistry, 6, pp. 4305-4321.

Shi, Q., Vitchuli, N., Nowak, J., Jane, M., Breidt, F., Bourham. M., Mater, J. One-step synthesis of silver nanoparticle-filled nylon 6 nanofibers and their antibacterial properties. $J$. Mater. Chem, 21, pp. 10330.

Tadros, T.F. (1993). Industrial application of dispersions. Advances in Colloid and Interface Science, pp.46 1-47.

Wu, Y., Messer, B., Yang, P. (2001). Superconducting $\mathrm{MgB}_{2}$ Nanowires. Adv. Mater, 13, pp. 1487-1489.

Xia, Y., Yang, P., Sun, Y., Wu, Y., Gate, B., Yin, Y., Kim, F., Yan, H. (2003). One-Dimensional Nanostructures: Synthesis, Characterization, and Applications. Adv. Mater, 15, pp. 353-389.

Ying, J.Y., Mehert, C.P., Wong, M.S. (1999). Synthesis and applications of supramolecular-templated mesoporous materials. Angewandte Chemie, 38, pp. 56-77.

Zhang, M. Q., Rong, M. Z., Friedrich, K. (2003). Processing and properties of 
nonlayered nanoparticle reinforced thermoplastic composites. in: 'Handbook of organicinorganic hybrid materials and nanocomposite. American Science Publishers, Boston, pp.113-150.

functionalized metalloporphyrins fixated within ultralarge-pore transition metal-doped silicate supports. Chemical Communications, 12, pp. 1103-1104.

Zhang, L., Sun, T., Ying, J.Y. (1999).

Oxidation catalysis over

\section{How to cite this article:}

Rebaz A. Omar, Awara K. Smail and Karzan A. Omar. 2016. Study on the Activity of Ag/Nylon 6, 10 Nanocomposite Against Escherichia coli. Int.J.Curr.Microbiol.App.Sci.5(4): 935-941. doi: http://dx.doi.org/10.20546/ijcmas.2016.504.106 